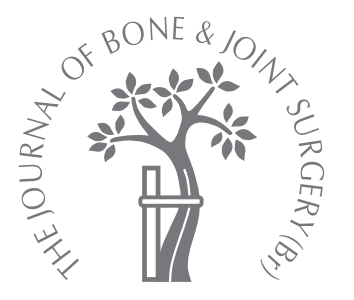

- ASPECTS OF CURRENT MANAGEMENT

\title{
Posterolateral rotatory instability of the elbow
}

C. P. Charalambous, J. K. Stanley

From Wrightington Hospital, Wigan, England
C. P. Charalambous, $\mathrm{MBChB}$ MSc, FRCS(Tr \& Orth)

Orthopaedic Surgeon

J. K. Stanley, MCh(Orth),

FRCS, FRCSEd, Professor of

Upper Limb Surgery

Department of Upper Limb

Surgery

Wrightington Hospital, Hall

Lane, Appley Bridge, Wigan

WN6 9EP, UK.

Correspondence should be sent to $\mathrm{Mr}$ C. P. Charalambous at

F.204, 159 Hathersage Road,

Manchester M13 OHX, UK;

e-mail:

bcharalambos@hotmail.com

(C2008 British Editorial Society

of Bone and Joint Surgery

doi:10.1302/0301-620X.90B3 $19868 \$ 2.00$

$J$ Bone Joint Surg $[\mathrm{Br}]$

2008;90-B:272-9.

\begin{abstract}
Posterolateral rotatory instability is the most common type of symptomatic chronic instability of the elbow. In this condition the forearm complex rotates externally in relation to the humerus, causing posterior subluxation or dislocation of the radial head. The lateral ligament complex, radial head and coronoid process are important constraints to posterolateral rotatory instability, and their disruption is involved in the pathogenesis of this condition. The diagnosis relies on a high index of clinical suspicion, active and passive apprehension tests, and examination under anaesthesia. Surgical treatment has given consistently successful results. Open reconstruction of the lateral ligaments with a tendon graft has been the procedure of choice, with arthroscopic techniques emerging as a potential alternative.
\end{abstract}

Posterolateral rotatory instability of the elbow is a condition in which the radius and ulna rotate externally in relation to the distal humerus, leading to posterior displacement of the radial head relative to the capitellum (Fig. 1). The proximal radioulnar joint is intact and both forearm bones rotate as a single unit. This differentiates posterolateral rotatory instability from isolated dislocation of the radial head, where the proximal radioulnar joint is disrupted and the ulnohumeral articulation is intact. Posterolateral rotatory instability is considered to be the most common type of symptomatic chronic instability of the elbow. Since the term was originally coined in $1991,{ }^{1}$ our understanding of this condition has expanded. This review aims to describe our current knowlege of the pathogenesis, presentation, diagnosis and management of chronic posterolateral rotatory instability of the elbow.

Biomechanics and underlying pathology The main static constraints to posterolateral laxity are the lateral ligament complex, the radial head and the coronoid process, with a smaller contribution from the common extensor origin. The role of dynamic stabilisers is not fully understood, although the extensor mass and the anconeus muscle may be involved. ${ }^{2}$ Deficiency of these constraints may lead to instability.

\section{The lateral ligament complex}

The lateral ligament complex is the primary constraint to posterolateral rotatory instabil- ity, limiting external rotation of the radius and ulna relative to the humerus. Traditionally it has been described anatomically as having three components; the annular ligament, the radial collateral ligament and the lateral ulnar collateral ligament. ${ }^{3,4}$ The annular ligament has been described as passing from the anterior margin of the sigmoid notch to the supinator crest encircling the radial head. The radial collateral ligament passes from the lateral epicondyle to insert into the annular ligament and the lateral ulnar collateral ligament from the lateral epicondyle to the supinator crest of the ulna. The lateral ulnar collateral ligament was considered the main constraint to posterolateral rotatory instability. This led to the recommendation that surgically incising the lateral ligament complex was safe, provided its most posterior part, the lateral ulnar collateral ligament, was not damaged. ${ }^{5}$ However, this description of the lateral ligament complex has been challenged by anatomical studies which fail to demonstrate a distinct prominent lateral ulnar collateral ligament, ${ }^{6-9}$ and by biomechanical investigations which show that the whole of the lateral ligament complex, rather than simply its posterior part, contributes to posterolateral constraint. ${ }^{10-14}$ We agree with those who consider the lateral ligament complex to be a continuous ligamentous sheet passing from the lateral humeral epicondyle to the supinator crest of the ulna and the sigmoid notch, and feel that any disruption of this may contribute to instability. 


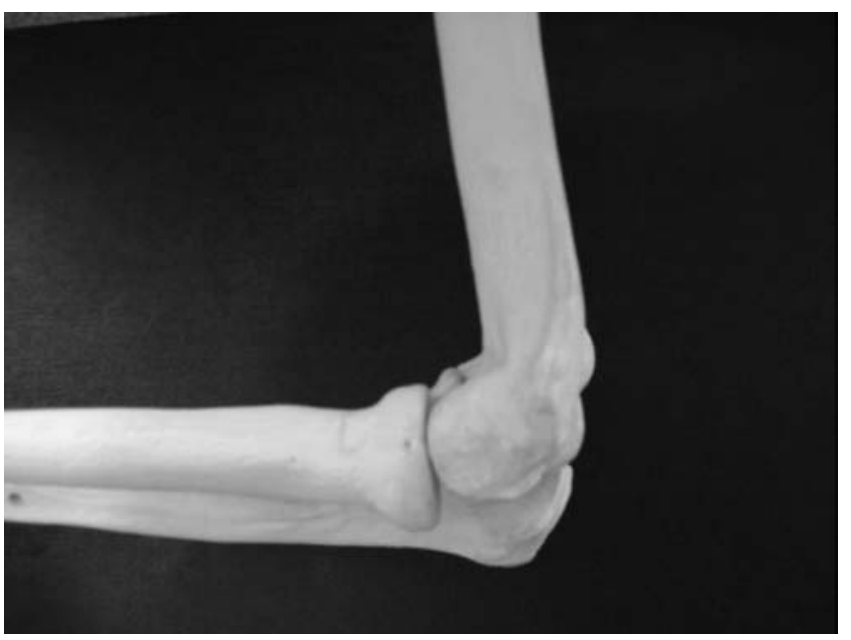

Fig. 1a

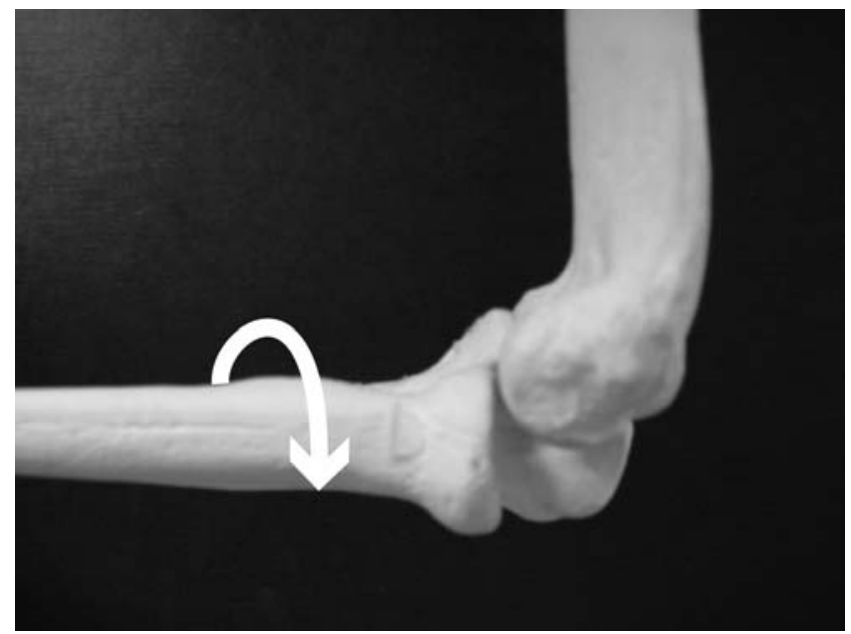

Fig. 1b

Photographs showing a) the intact elbow and b) external rotation of the forearm complex (radius and ulna) with regard to the distal humerus leading to posterior displacement of the radial head relative to the capitellum.

Disruption of the lateral ligament complex may be due to trauma, to chronic attentuation or be iatrogenic. Posttraumatic disruption is the most common, as this is the first ligament to be damaged in posterolateral subluxation or dislocation of the elbow ${ }^{15}$ and is usually avulsed from its distal humeral origin. ${ }^{16}$ In traumatic posterolateral dislocation, soft-tissue disruption occurs in a circular fashion from lateral to medial (Horii circle, Stage I to III $^{17}$ ). In stage I injuries, the lateral ligament complex is disrupted, in stage II the anterior and posterior capsule is torn, and in stage III the medial collateral ligament (MCL) also ruptures. $^{18}$

Iatrogenic injury may follow open or arthroscopic release of the lateral epicondyle, ${ }^{18}$ or surgical approaches to the lateral side of the elbow joint and the head of the radius. ${ }^{19}$ The Kocher approach ${ }^{5}$ utilises the interval between anconeus and extensor carpi ulnaris, incising the more anterior part of the lateral ligament complex. The Wrightington approach to the radial head, which has recently been described, lifts off anconeus from the ulna wih an osteotomy of the ulnar attachment of the lateral ligament complex, which is subsequently fixed back to its origin. ${ }^{20}$ This avoids incising the substance of the lateral ligament complex and allows it to be re-tensioned when it is re-attached at the osteotomy site, which could potentially minimise any posterolateral laxity. Posterolateral rotatory instability has been reported after treatment of lateral epicondylitis by serial steroid injections. ${ }^{21}$ Whether rupture of the lateral ligament complex was iatrogenic due to administration of steroid or the result of the degenerative process involving the common extensor origin was difficult to determine.

Chronic attentuation of the lateral ligament complex may occur in long-standing cubitus varus. ${ }^{22,23}$ In such chronic conditions the ligament stretches, losing its normal tension. In addition, the direction of pull of triceps is altered so that it exerts an external rotatory moment on the ulna, an important component of posterolateral rotatory instability. ${ }^{23}$ Beuerlein et $\mathrm{al}^{24}$ showed in cadaver specimens that $20^{\circ}$ of cubitus varus causes ulnohumeral widening indicative of posterolateral rotatory instability. However, the development of clinical posterolateral rotatory instability depends not only on the absolute amount of varus deformity but also on its duration and the levels of the patient's activity. This would explain the development of symptomatic posterolateral rotatory instability in angles of cubitus varus smaller than those predicted biomechanically. ${ }^{23}$ Chronic attentuation of the lateral ligament complex may also be secondary to overuse, such as in patients with poliomyelitis who use crutches to walk. Finally, the lateral ligament complex may be inherently lax in conditions of generalised ligamentous hyperlaxity.

\section{Radial head and capitellum}

The radial head is a significant constraint to posterolateral rotatory instability, contributing to stability by providing osseous congruency and tensioning the lateral ligament complex. Its excision may slacken and de-function the lateral ligament complex. Following excision of the radial head in human cadavers, Jensen et $\mathrm{al}^{25}$ found a $7.1^{\circ}$ mean increase in external rotatory laxity of the forearm relative to the humerus. Schneeberger, Sadowski and Jacob ${ }^{26}$ reported doubling of the external rotatory laxity despite intact medial and lateral ligaments. These studies are supported by the development of posterolateral rotatory instability in patients in whom the radial head was excised following a comminuted fracture. ${ }^{27}$ In the absence of the head the proximal radial stump subluxes posteriorly giving rise to symptoms of posterolateral rotatory instability. 
Table I. Clinical tests for posterolateral rotatory instability of the elbow

\begin{tabular}{ll}
\hline Test & Description \\
\hline Lateral pivot-shift test $^{1}$ & Patient supine, affected limb overhead. With forearm supinated, valgus and axial loading \\
& applied, elbow is flexed from full extension. In posterolateral rotatory instability as the \\
& elbow is flexed the radial head subluxes/dislocates, seen as an osseous prominence pos- \\
& terolaterally. With flexion beyond $40^{\circ}$ the radial head suddenly reduces with a palpable \\
& and visible clunk. The test may also be done starting with the elbow flexed and then \\
& extending, reversing the above sequence. The test is best done under general anaesthe- \\
& sia for radial head dislocation and relocation to be seen.
\end{tabular}

Lateral pivot-shift apprehension test ${ }^{1}$

Posterolateral rotatory drawer test ${ }^{17}$

Table-top relocation test ${ }^{35}$

Active floor push-up sign ${ }^{36}$

Chair sign ${ }^{36}$
The above manoeuvre is performed with the patient awake. The test is positive if apprehension occurs.

Patient supine, affected limb overhead, elbow flexed $40^{\circ}$. Anteroposterior force is applied to the radius and ulna with the forearm in external rotation. This aims to sublux the forearm away from the humerus on the lateral side, pivoting on the intact medial ligaments. Under general anaesthesia the radial head is seen dislocating, whereas with the patient awake apprehension occurs.

Patient performs a press-up on the edge of a table using one arm, with the forearm in supination. In the presence of instability, apprehension occurs at about $40^{\circ}$ flexion. The manoeuvre is repeated while the examiner's thumb presses on the radial head, preventing subluxation. The test is positive if thumb pressure relieves apprehension.

Patient pushes off the floor with elbows flexed $90^{\circ}$, forearms supinated and arms abducted. The test is positive if apprehension or radial head dislocation occurs as the elbow is extended.

Patient seated with elbows flexed $90^{\circ}$, forearms supinated and arms abducted. Patient tries to rise from the chair pushing down only with the arms. The test is positive if apprehension or radial head dislocation occurs with elbow extension.

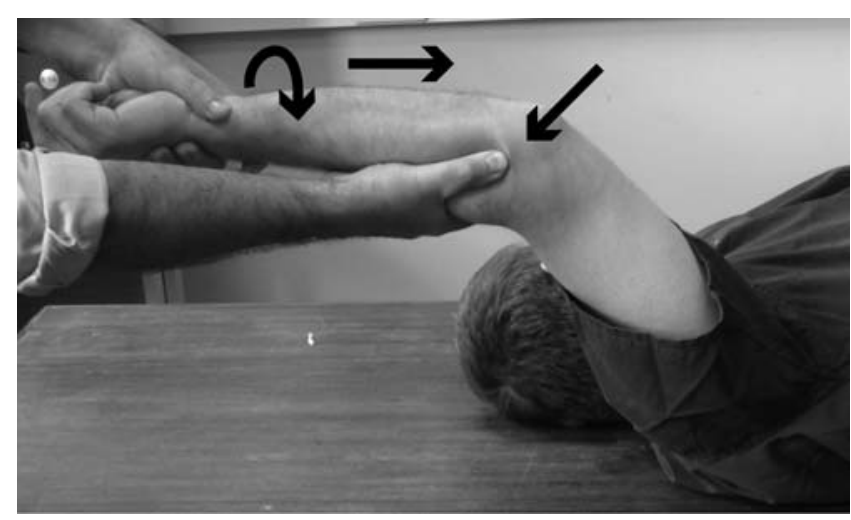

Fig. 2

Photograph showing the lateral pivot-shift test. ${ }^{1}$ Application of external rotation, valgus and axial loading to the elbow causes apprehension or radial head subluxation/dislocation.

This potential complication must be considered when dealing with fractures of the radial head, and may be avoided by arthroplasty rather than simple excision, even in the presence of an intact medial collateral ligament.

The capitellum has not been extensively investigated in the pathogenesis of posterolateral rotatory instability. However, loss of capitellar height would be expected to slacken the lateral ligament complex, causing posterolateral rotatory instability. Additionally, changes in the capitellar struc- ture can alter the congruency of the radiocapitellar articulation, an important component of stability. Such changes may be due to a fracture, or to osteochondritis dissecans. ${ }^{28}$ To avoid such complications every attempt should be made to fix capitellar fractures, with excision of the fragments used as a last resort.

\section{Coronoid process}

The coronoid process is increasingly recognised as an important elbow stabiliser, acting as a constraint to posterior ulnohumeral displacement on axial ${ }^{29}$ and varus ${ }^{26,30-32}$ loading. Coronoid deficiency is most commonly post-traumatic. Regan and Morrey ${ }^{33}$ classified coronoid fractures according to the proportion of the coronoid process involved. Stage I fractures involve the tip of the coronoid, stage II up to $50 \%$, and stage III more than $50 \%$ of the height of the coronoid. In a biomechanical cadaver study, isolated stage I fractures did not increase posterolateral laxity, but stage II fractures with $50 \%$ reduction in coronoid height resulted in a $28 \%$ increase in external rotation of the forearm relative to the humerus. When combined with excision of the radial head, loss of $30 \%$ of coronoid height ${ }^{26}$ fully destabilised cadaver elbows, leading to ulnohumeral dislocation even in the presence of intact ligaments. Furthermore, in such combined injuries, when $50 \%$ of the coronoid height was lost, isolated prosthetic replacement of the radial head did not fully restore elbow stability. These laboratory observations are supported clinically by patients presenting with chronic posterolateral rotatory instability following an ununited coronoid fracture. In these 


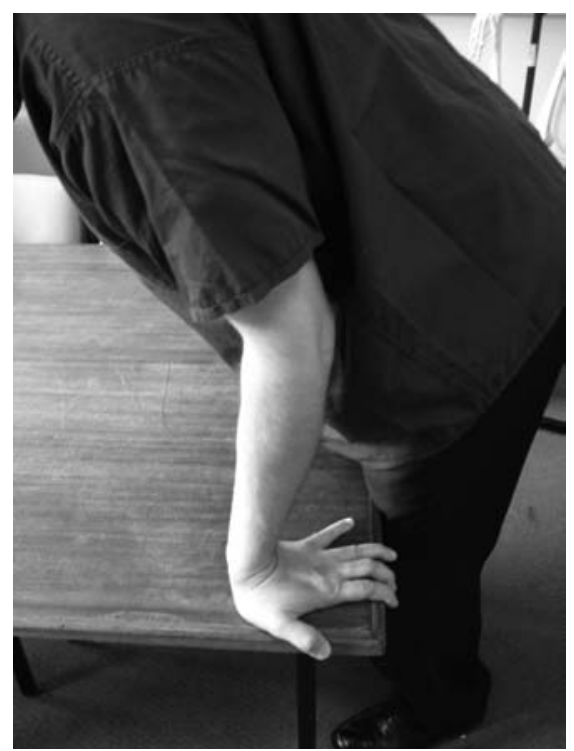

Fig. 3a

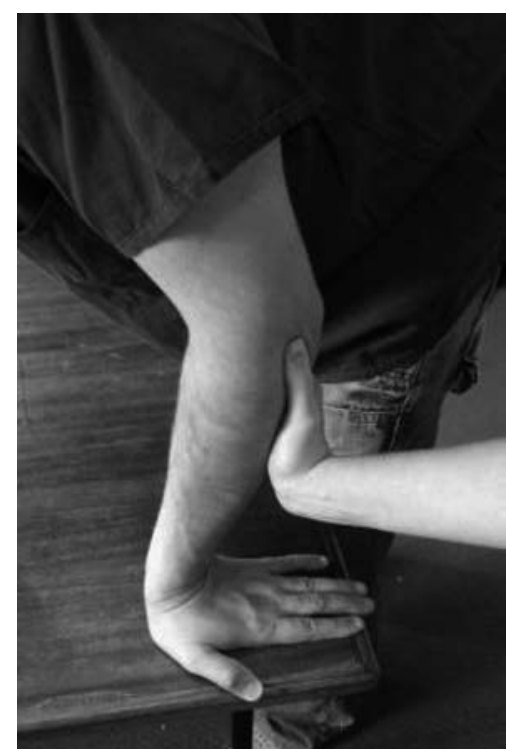

Fig. 3b

Photographs showing the table-top relocation test. ${ }^{35}$ a) A press-up on the edge of a table with the forearm in supination causes apprehension if instability is present. b) The examiner's thumb pressing on the radial head prevents displacement and relieves apprehension.

patients stability has been restored by bone grafting and reconstruction of the coronoid. ${ }^{34}$ Therefore, in dealing with acute coronoid fractures consideration must be given to the possibility of posterolateral rotatory instability and the need for surgical fixation.

\section{Common extensor origin}

The common extensor muscle mass and its strong intermuscular septa cross the lateral side of the elbow and are important static secondary constraints to posterolateral rotatory instability. ${ }^{9}$ This is in addition to any possible dynamic effect. Disruption of the common extensor mass has been reported in $66 \%$ of elbow dislocations undergoing surgery. ${ }^{16}$ Extensive release of the extensor origin in surgical treatment of lateral epicondylitis should be avoided as this may compromise elbow stability, especially if the underlying lateral ligament complex is attenuated.

\section{Clinical presentation, investigations and diagnosis}

Patients may present with a spectrum ranging from vague symptoms in the elbow to frank recurrent posterolateral dislocation. Lateral elbow pain, clicking, popping and snapping are not uncommon. Symptoms are often brought on by activities such as pushing up from a chair or doing press-ups, which place the elbow in an unstable position of external rotation of the forearm with valgus and axial loading of the elbow. A previous history of trauma or surgery on the lateral side of the elbow should be sought.

Clinical examination aims to identify signs of previous trauma or surgery, ulnohumeral alignment and range of movement. Several clinical tests for posterolateral rotatory instability have been described (Table I, Figs 2 to 5). 1,17,35,36 All these place the elbow in a position of maximal instability, with a combination of external rotation of the forearm, valgus and axial loading, which try to reproduce either the symptoms or displacement of the radial head. It is important to look for coexistent valgus or varus instability as well as generalised ligamentous hyperlaxity.

Further investigations can contribute to the diagnosis, though their value is often limited. Plain radiography may show an avulsion fracture of the origin or insertion of the lateral ligament complex. It can also demonstrate the integrity of the radial head, coronoid process and capitellum, and the presence of degenerative changes. Impression fractures of the radial head or the posterior part of the capitellum, analogous to the Hill-Sachs lesion of dislocation of the shoulder, ${ }^{37}$ may be seen. The drop sign (an ulnohumeral distance $>4 \mathrm{~mm}$ on the plain lateral film of the unstressed elbow) can be indicative of residual instability following elbow dislocation. ${ }^{38}$ Lateral screening of the elbow during the pivot shift test may show posterior displacement of the radial head and ulnohumeral widening. The value of MRI in the diagnosis of posterolateral rotatory instability remains controversial, although Potter et $\mathrm{al}^{39}$ found $100 \%$ correlation between abnormal MRI findings of the lateral ligaments and clinical posterolateral rotatory instability, this has not, however, been confirmed by others ${ }^{40-42}$ who attempted to describe the lateral ulnar collateral ligament in normal and injured elbows. This may be partly because these studies tried to identify a distinct, prominent lateral 


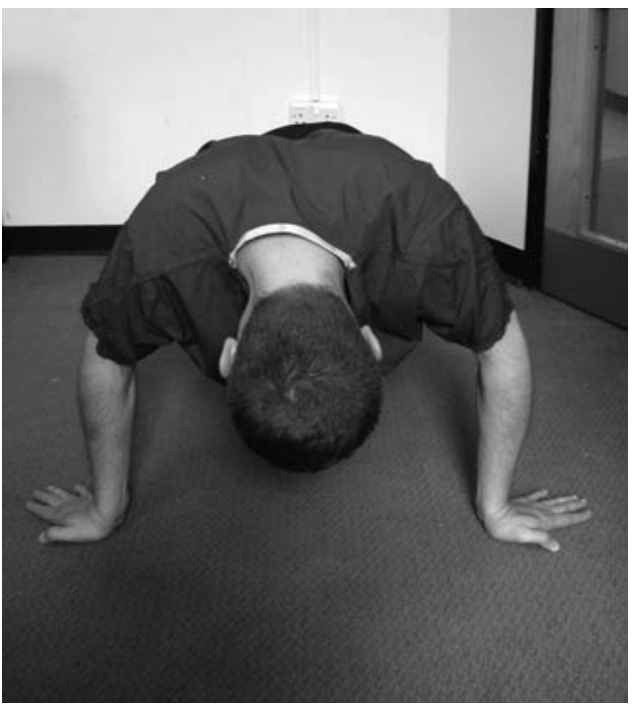

Fig. 4

Photograph showing the active floor push-up sign. ${ }^{36}$

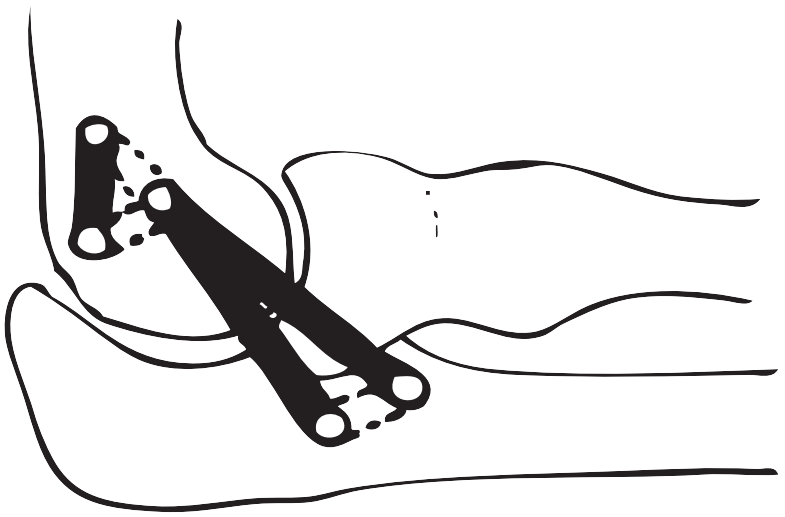

Fig. 6

Diagram showing lateral ligament reconstruction using ulnar and humeral drill holes and bone tunnels.

ulnar-collateral band, which anatomical studies increasingly suggest may not exist. Finally, arthroscopic examinations of the elbow may show posterior displacement of the radial head, an elongated lateral ligament complex or widening of the lateral joint space.

The diagnosis of posterolateral rotatory instability remains a clinical one with a combination of the history, active and passive apprehension tests, and examination of the elbow under anaesthesia. Apprehension is all that can be elicited because the patient is usually awake and general

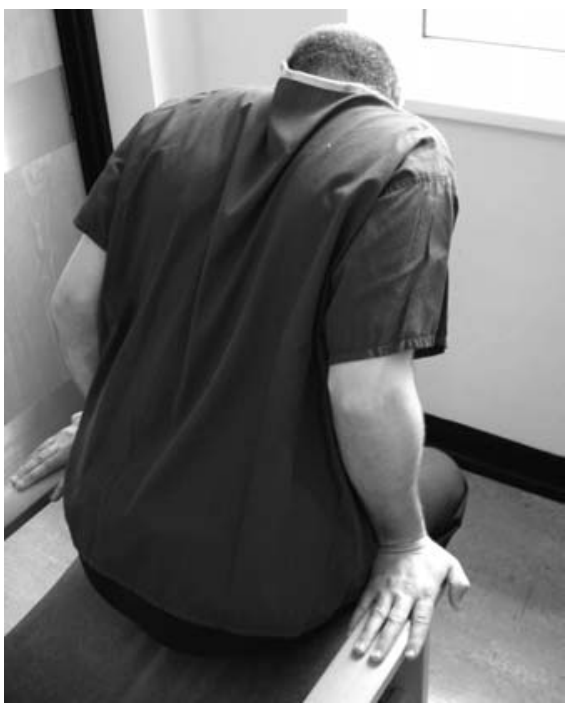

Fig. 5

Photograph showing the chair sign. ${ }^{36}$ In the presence of instability, on attempting to rise from a chair pushing down only with the arms, and with the forearms supinated apprehension or radial head dislocation occurs as the elbow extends.

anaesthesia is needed to demonstrate displacement of the radial head. With the patient under general anaesthesia we initially examine for valgus and varus instability in $30^{\circ}$ of elbow flexion to unlock the olecranon fossa. Testing for valgus instability with the forearm in supination may give a false positive result in the presence of posterolateral rotatory instability, and so we also test this with the forearm in pronation. Inability to demonstrate varus instability does not imply that the lateral ligaments are intact, as the ulnohumeral articulation is the main constraint to varus. We test for posterolateral rotatory instability using the pivot shift and posterolateral drawer tests. If these fail to demonstrate instability we screen the elbow using the image intensifier while performing the pivot-shift test.

\section{Management}

Management of chronic posterolateral rotatory instability of the elbow depends on the severity of the patient's symptoms. Avoiding provocative manoeuvres and bracing to limit supination and valgus loading may suffice in some, but in significantly-affected patients surgery is preferred.

Surgical management aims at re-attaching, retensioning or reconstructing the lateral ligament complex, dealing with bone deficiency of the radiocapitellar and ulnohumeral articulation by replacement of the radial head or coronoid reconstruction, and correcting any varus deformity of the humerus by osteotomy. One or all of these may be necessary, depending on the underlying pathology.

Reattachment and retensioning of the lateral ligament complex with imbrication and advancement have been 
Table II. Studies reporting the outcome of isolated lateral ligament reconstruction for posterolateral rotatory instability of the elbow

\begin{tabular}{|c|c|c|c|c|c|}
\hline Study & $\begin{array}{l}\text { Number of } \\
\text { cases }\end{array}$ & Graft & Fixation type & $\begin{array}{l}\text { Mean follow-up in } \\
\text { mths (range) }\end{array}$ & $\begin{array}{l}\text { Cases with persistent } \\
\text { instability without } \\
\text { further injury }\end{array}$ \\
\hline Sanchez-Sotelo et al ${ }^{43}$ & 32 & $\begin{array}{l}\text { Various autografts and } \\
\text { allografts }\end{array}$ & Bone tunnels & 69.6 (24 to 182.4 ) & 2 \\
\hline Olsen and Søjbjerg ${ }^{45}$ & 18 & Triceps fascia & $\begin{array}{l}\text { Humeral bone tunnels, } \\
\text { ulnar suture anchors }\end{array}$ & 44 (14 to 88 ) & 4 \\
\hline Eygendaal $^{46}$ & 12 & Triceps tendon & Interference screws & 23 (17 to 48 ) & 1 \\
\hline Lee and $\mathrm{Teo}^{44}$ & 6 & $\begin{array}{l}\text { Palmaris longus, semi- } \\
\text { tendinosus }\end{array}$ & Bone tunnels & 27.8 (9 to 52$)$ & 0 \\
\hline DeLaMora and Hausman ${ }^{19}$ & 5 & Distally-based triceps fascia & Humeral bone tunnels & Not available & 0 \\
\hline Rizio $^{47}$ & 1 & Fascia lata & Bone tunnels & 34 & 0 \\
\hline
\end{tabular}

used, but reconstruction with a graft may provide a more stable construct. Current techniques ${ }^{19,43-48}$ repair that part of the lateral ligament complex which passes from the lateral humeral epicondyle to the supinator crest of the ulna. A tendon graft is used, with fixation achieved by bone tunnels, anchor sutures or interference screws. Although an autograft of palmaris longus is commonly employed, the use of triceps fascia, semitendinosus, gracilis, plantaris, tendo Achillis, and synthetic devices has been reported. ${ }^{43,48}$ In performing tendon reconstruction using bone tunnels, two drill holes are made at the ulnar supinator crest, connected by a tunnel. A large suture is passed through this tunnel and its free ends are held with a heavy artery clip on to the lateral humeral epicondyle. The elbow is taken through flexion and extension to detect the isometric point on the distal humerus, where the site of entry for the graft is then drilled. Two additional humeral holes are drilled, and all three are connected by tunnels. The graft passes through the ulnar tunnel, through the isometric point of the humerus, through the humeral tunnels, and is sewn back to itself (Fig. 6), with the elbow held in $30^{\circ}$ to $40^{\circ}$ of flexion and full pronation. ${ }^{17}$

Arthroscopically assisted repair of the avulsed lateral ligament complex has been described. ${ }^{49}$ Similarly, the use of arthroscopic electrothermal shrinkage of the lateral ligament complex as the sole treatment for posterolateral elbow instability has been reported. ${ }^{50}$

\section{Results of surgery}

A review of the literature reveals a satisfactory outcome in most patients treated surgically, with resolution of instability, improvement of pain and maintenance of joint movement. The outcome is less good in those with degenerative changes or generalised ligamentous hyperlaxity. We identified six studies looking at isolated ligamentous repair or reconstruction in the treatment of chronic posterolateral rotatory instability (Table II). ${ }^{19,43-47}$ A series from the Mayo clinic $^{43}$ described 12 patients treated by lateral ligament complex repair with humeral reattachment or imbrication and 32 by reconstruction; five had persistent instability, three treated by repair and two by reconstruction. Surgery led to relief of pain and improvement or maintenance of movement in most. The mean post-operative Mayo elbow performance score was $85 ; 17$ patients were rated excellent, 17 good and ten fair. The results of ligament reconstruction were better than those for repair. Lee and $\mathrm{TeO}^{44}$ reported ten patients with posterolateral rotatory instability, four having lateral ligament imbrication and advancement and six tendon graft reconstruction. Post-operatively, all had a negative pivot shift test, reported no or mild pain, and retained functional movement. Olsen and Søjbjerg ${ }^{45}$ used a triceps tendon graft to reconstruct the lateral ligament complex in 18 patients. Post-operatively, 14 had a stable elbow but four continued to have apprehension on the pivot-shift test. Loss of movement of $10^{\circ}$ to $15^{\circ}$ was noted in only three; 13 patients had no or only occasional residual pain, and five reported moderate pain. The mean post-operative Mayo elbow score was 92. DeLaMora and Hausman ${ }^{19}$ recorded five patients treated by ligamentous reconstruction using a distally based triceps fascia strip. The pivot shift test became negative in all and the mean postoperative range of movement was $10^{\circ}$ to $135^{\circ}$. Eygendaal ${ }^{46}$ described 12 cases treated by ligament reconstruction using triceps tendon fixed with interference screws. All but one had a stable elbow and pain improved in most; six patients lost $5^{\circ}$ to $10^{\circ}$ of extension, but none lost flexion. Rizio ${ }^{47}$ performed ligament reconstruction in a skeletally immature 11-year-old with post-traumatic recurrent elbow dislocation. A fascia lata allograft was fixed using bone tunnels. As the bone tunnels were proximal to the humeral epiphysis and distal to the olecranon epiphysis no growth disturbance was seen. At follow-up there was no further instability and a full range of movement. The Sheffield Elbow Unit recently presented 11 patients treated by reconstruction of the lateral ligament in eight and of the medial in three for chronic posterolateral rotatory instability or valgus instability. $^{48}$ At a mean follow-up of three years only one patient, with generalised ligamentous hyperlaxity due to the Ehlers-Danlos syndrome, was still unstable. ${ }^{48}$

Published techniques ${ }^{43-48}$ of ligament reconstruction report successful results in most patients, even though they only attempt to reconstruct that part of the lateral ligament complex passing from the lateral epicondyle to the supinator crest. Given our current understanding of the complex 
functional structure of the lateral ligament complex, it will be interesting to see whether more anatomical techniques of reconstruction, replacing the whole of the lateral ligament complex rather than simply its more posterior part, can further improve the results.

Arthroscopic treatment of posterolateral rotatory instability has been reported. ${ }^{50}$ Spahn et al ${ }^{50}$ described 21 patients treated with arthroscopic thermal ligament shrinkage at a mean follow-up of 2.5 years. The positive pivot-shift test became negative after surgery, and the mean Mayo elbow performance score increased from 44 to 77 . There were no recurrent dislocations of the elbow or complications of thermal ablation.

The results of bony surgery in isolation or combined with ligament reconstruction are also promising. O'Driscoll et $\mathrm{al}^{23}$ reported 22 cases of posterolateral rotatory instability secondary to post-traumatic or congenital cubitus varus. Tardy instability developed 20 to 30 years after the deformity. In seven cases ligament reconstruction and osteotomy were performed, in ten ligament reconstruction alone, in four osteotomy alone, and in one total elbow arthroplasty. At a mean follow-up of three years, only three of the 22 patients had persistent instability. Movement was maintained or improved in all. The mean post-operative Mayo elbow score was 87 . Hall and $\mathrm{McKee}^{27}$ reported seven patients who developed posterolateral rotatory instability following excision of the radial head for comminuted fractures. In three, replacement of the radial head and reconstruction of the lateral ligament complex was performed and their symptoms improved, the mean Mayo elbow score rising from 55 to 81.5 . Okazaki et $\mathrm{al}^{34}$ reported three patients with chronic posterolateral rotatory instability that was attributed at least partly to post-traumatic coronoid deficiency; two had nonunion of a coronoid fracture and one a flattened trochlear notch. Coronoid reconstruction with an iliac crest or humeral bone autograft helped restore stability.

\section{Conclusion}

Disruption of the lateral ligament complex, radial head and coronoid plays an important role in the pathogenesis of posterolateral rotatory instability of the elbow. The diagnosis of this condition remains clinical, with examination under anaesthesia being useful. Open surgical reconstruction of the lateral ligaments restores stability in most patients, with arthroscopic techniques emerging as a potential alternative. Bony procedures may be needed in those with a varus deformity of the humerus or deficiency of the radial head or coronoid. Understanding the complex structure of the lateral stabilisers of the elbow and respecting their integrity during surgery may help prevent this condition in some patients.

\section{References}

1. O'Driscoll SW, Bell DF, Morrey BF. Postero-lateral rotatory instability of the elbow. J Bone Joint Surg [Am] 1991;73-A:440-6.

2. Basmajian JV, Griffin RW. Function of anconeus muscle: an electromyographic study. J Bone Joint Surg [Am] 1972;54-A:1712-14.
3. Morrey BF, An KN. Functional anatomy of the ligaments of the elbow. Clin Orthop 1985;201:84-90.

4. O'Driscoll SW, Horii E, Morrey BF, Carmichael SW. Anatomy of the ulnar part of the lateral collateral ligament of the elbow. Clin Anat 1992;5:296-303.

5. Patterson SD, Bain GI, Mehta JA. Surgical approaches to the elbow. Clin Orthop 2000;370:19-33.

6. Imatani J, Ogura T, Morito Y, Hashizume H, Inoue H. Anatomic and histologic studies of lateral collateral ligament complex of the elbow joint. J Shoulder Elbow Surg 1999;8:625-7.

7. Takigawa N, Ryu J, Kish VL, Kinoshita M, Abe M. Functional anatomy of the lateral collateral ligament complex of the elbow: morphology and strain. J Hand Surg [Br] 2005;30:143-7.

8. OIsen BS, Vaesel MT, Søjbjerg J0, Helmig P, Sneppen O. Lateral collateral ligament of the elbow joint: anatomy and kinematics. J Shoulder Elbow Surg 1996;5:103-12.

9. Cohen MS, Hastings $\mathbf{H}$ 2nd. Rotatory instability of the elbow: the anatomy and role of the lateral stabilizers. J Bone Joint Surg [Am] 1997;79-A:225-33.

10. Seki A, Olsen BS, Jensen SL, Eygendaal D, Søjbjerg JO. Functional anatomy of the lateral collateral ligament complex of the elbow: configuration of $Y$ and its role. $J$ Shoulder Elbow Surg 2002;11:53-9.

11. McAdams TR, Masters GW, Srivastava S. The effect of arthroscopic sectioning of the lateral ligament complex of the elbow on postero-lateral rotatory stability. J Shoulder Elbow Surg 2005;14:298-301.

12. OIsen BS, Søjbjerg J0, Dalstra M, Sneppen 0. Kinematics of the lateral ligamentous constraints of the elbow joint. J Shoulder Elbow Surg 1996;5:333-41.

13. Dunning CE, Zarzour ZD, Patterson SD, Johnson JA, King GJ. Ligamentous stabilizers against posterolateral rotatory instability of the elbow. J Bone Joint Surg [Am] 2001;83-A:1823-8.

14. Deutsch SR, Olsen BS, Jensen SL, Tyrdal S, Sneppen O. Ligamentous and capsular restraints to experimental posterior elbow joint dislocation. Scand J Med Sci Sports 2003;13:311-16.

15. O'Driscoll SW, Morrey BF, Korinek S, An KN. Elbow subluxation and dislocation: a spectrum of instability. Clin Orthop 1992;280:186-97.

16. McKee MD, Schemitsch EH, Sala MJ, O'Driscoll SW. The pathoanatomy of lateral ligamentous disruption in complex elbow instability. J Shoulder Elbow Surg 2003;12:391-6.

17. O'Driscoll SW, Jupiter JB, King GJW, Hotchkiss RN, Morrey BF. The unstable elbow. J Bone Joint Surg [Am] 2000;82-A:724-37.

18. Morrey BF. Reoperation for failed surgical treatment of refractory lateral epicondylitis. J Shoulder Elbow Surg 1992;1:47-55.

19. DeLaMora SN, Hausman M. Lateral ulnar collateral ligament reconstruction using the lateral triceps fascia. Orthopedics 2002;25:909-12.

20. Stanley JK, Penn DS, Wasseem M. Exposure of the head of the radius using the Wrightington approach. J Bone Joint Surg [Br] 2006;88-B:1178-82.

21. Kalainov DM, Cohen MS. Postero-lateral rotatory instability of the elbow in association with lateral epicondylitis: a report of three cases. J Bone Joint Surg [Am] 2005;87-A:1120-5

22. Abe M, Ishizu T, Morikawa J. Postero-lateral rotatory instability of the elbow after post-traumatic cubitus varus. J Shoulder Elbow Surg 1997;6:405-9.

23. O'Driscoll SW, Spinner RJ, McKee MD, et al. Tardy postero-lateral rotatory instability of the elbow due to cubitus varus. J Bone Joint Surg [Am]2001;83-A:135869.

24. Beuerlein MJ, Reid JT, Schemitsch EH, McKee MD. Effect of distal humeral varus deformity on strain in the lateral ulnar collateral ligament and ulnohumeral joint stability. J Bone Joint Surg [Am] 2004;86-A:2235-42

25. Jensen SL, Olsen BS, Tyrdal S, Søjbjerg J0, Sneppen 0. Elbow joint laxity after experimental radial head excision and lateral collateral ligament rupture: efficacy of prosthetic replacement and ligament repair. J Shoulder Elbow Surg 2005;14:78-84.

26. Schneeberger AG, Sadowski MM, Jacob HA. Coronoid process and radial head as postero-lateral rotatory stabilizers of the elbow. J Bone Joint Surg [Am] 2004;86A:975-82.

27. Hall JA, McKee MD. Posterolateral rotatory instability of the elbow following radial head resection. J Bone Joint Surg [Am] 2005;87-A:1571-9.

28. Klekamp J, Green NE, Mencio GA. Osteochondritis dissecans as a cause of developmental dislocation of the radial head. Clin Orthop 1997;338:36-41.

29. Closkey RF, Goode JR, Kirschenbaum D, Cody RP. The role of the coronoid process in elbow stability: a biomechanical analysis of axial loading. J Bone Joint Surg [Am]2000;82-A:1749-53.

30. Beingessner DM, Dunning CE, Stacpoole RA, Johnson JA, King GJ. The effect of coronoid fractures on elbow kinematics and stability. Clin Biomech 2007;22:18390 
31. Hull JR, Owen JR, Fern SE, Wayne JS, Boardman ND 3rd. Role of the coronoid process in varus osteoarticular stability of the elbow. J Shoulder Elbow Surg 2005;14:441-6.

32. Deutsch SR, Jensen SL, Tyrdal S, Olsen BS, Sneppen O. Elbow joint stability following experimental osteoligamentous injury and reconstruction. J Shoulder Elbow Surg 2003;12:466-71.

33. Regan W, Morrey BF. Fractures of the coronoid process of the ulna. J Bone Joint Surg [Am] 1989;71-A:1348-54

34. Okazaki M, Takayama S, Seki A, Ikegami H, Nakamura T. Posterolateral rotatory instability of the elbow with insufficient coronoid process of the ulna: a report of 3 patients. J Hand Surg [Am] 2007;32:236-9.

35. Arvind CH, Hargreaves DG. Tabletop relocation test: a new clinical test for posterolateral rotatory instability of the elbow. J Shoulder Elbow Surg 2006;15:707-8.

36. Regan W, Lapner PC. Prospective evaluation of two diagnostic apprehension signs for postero-lateral instability of the elbow. J Shoulder Elbow Surg 2006;15:344-6.

37. Faber KJ, King GJ. Posterior capitellum impression fracture: a case report associated with posterolateral rotatory instability of the elbow. J Shoulder Elbow Surg 1998;7:157-9.

38. Coonrad RW, Roush TF, Major NM, Basamania CJ. The drop sign, a radiographic warning sign of elbow instability. J Shoulder Elbow Surg 2005;14:312-17.

39. Potter HG, Weiland AJ, Schatz JA, Paletta GA, Hotchkiss RN. Posterolateral rotatory instability of the elbow: usefulness of MR imaging in diagnosis. Radiology 1997;204:185-9.

40. Carrino JA, Morrison WB, Zou KH, et al. Lateral ulnar collateral ligament of the elbow: optimization of evaluation with two-dimensional MR imaging. Radiology 2001;218:118-25
41. Terada N, Yamada H, Toyama Y. The appearance of the lateral ulnar collateral ligament on magnetic resonance imaging. J Shoulder Elbow Surg 2004;13:214-16.

42. Grafe MW, McAdams TR, Beaulieu CF, Ladd AL. Magnetic resonance imaging in diagnosis of chronic posterolateral rotatory instability of the elbow. Am J Orthop 2003;32:501-3

43. Sanchez-Sotelo J, Morrey BF, O'Driscoll SW. Ligamentous repair and reconstruction for posterolateral rotatory instability of the elbow. J Bone Joint Surg $[\mathrm{Br}]$ 2005;87-B:54-61.

44. Lee BP, Teo LH. Surgical reconstruction for posterolateral rotatory instability of the elbow. J Shoulder Elbow Surg 2003;12:476-9.

45. OIsen BS, Søjbjerg J0. The treatment of recurrent posterolateral instability of the elbow. J Bone Joint Surg [Br] 2003;85-B:342-6.

46. Eygendaal D. Ligamentous reconstruction around the elbow using triceps tendon. Acta Orthop Scand 2004;75:516-23.

47. Rizio L. Lateral ulnar collateral ligament reconstruction in a skeletally immature patient. Am J Sports Med 2005;33:439-42.

48. Qureshi F, Draviaraj K, Stanley D. Chronic instability of the elbow (abstract). BESS annual meeting, 2006.

49. Smith JP 3rd, Savoie FH 3rd, Field LD. Postero-lateral rotatory instability of the elbow. Clin Sports Med 2001;20:47-58.

50. Spahn G, Kirschbaum S, Klinger HM, Wittig R. Arthroscopic electrothermal shrinkage of chronic postero-lateral elbow instability: good or moderate outcome in 21 patients followed for an average of 2.5 years. Acta Orthop 2006;77:285-9. 